\title{
PENDIDIKAN INTEGRAL BERBASIS KARAKTER DI LEMBAGA PENDIDIKAN HIDAYATULLAH DI KUDUS JAWA TENGAH
}

\author{
Moh Rosyid ${ }^{1}$ \\ ${ }^{1}$ IAIN Kudus Jawa Tengah \\ 1Email; mrosyid72@yahoo.com
}

Diterima: 5 Juli 2021 | Disetujui: 15 Juli 2021 | Dipublikasikan : 17 Juli 2021

\begin{abstract}
Abstrak
Faktor yang melatarbelakangi dilakukannya riset ini adalah upaya memahami bahwa mencintai al-Quran perlu ditanamkan sejak usia dini agar mentradisi dengan membacanya secara tartil. Sekolah Dasar Islam Terpadu di bawah naungan Yayasan al-Aqsho Pesantren Hidayatullah di Kudus Jawa Tengah mempunyai kekhasan dalam menanamkan cinta al-Quran dalam pembelajaran. Tujuan riset ini untuk mendapatkan fakta kekhasan tersebut. Riset ini kategori riset yang datanya berbasis dari lokasi riset, diperoleh dari literatur, wawancara, dan observasi, analisis yang digunakan deskriptif kualitatif. Hasil riset, model pembelajarannya inquiri, project, and problem based learning, dan discovery learning. Ketiganya memadukan tiga gaya belajar yakni visual (penglihatan), auditory (pendengaran), dan kinetic (gerakan). Ekstrakulikulernya meliputi qiroah (membaca al-Quran dengan lagu merdu), kaligrafi (seni menulis huruf Arab/al-Quran), pramuka, panahan, pianika dan paduan suara, rebana, beladiri, jurnalistik, dan seni mewarnai. Kegiatan ekstra paling banyak peminatnya tilawah dan panahan, sedangkan yang paling sedikit peminatnya paduan suara. Hasil pembelajarannya, siswa akidahnya kokoh, berakhlak al-Quran, semangat beribadah, komitmen berjamaah sebagai bekal mewujudkan kecerdasan qolbu. Hal ini sebagaimana etos lembaganya yakni membuka hati dengan pendidikan integral berbasis karakter dan mewujudkan terciptanya generasi yang berakhlakul karimah, tertradisi membaca al-Quran, dan menghapalnya yang didukung dengan tenaga pendidik yang berkomitmen pendidik sejati.
\end{abstract}

Kata Kunci: Hidayatullah, generasi quran, dan berakhlakul karimah.

\begin{abstract}
[PENDIDIKAN INTEGRAL BERBASIS TAUHID DI LEMBAGA PENDIDIKAN HIDAYATULLAH KUDUS JAWA TENGAH] This research aims at behind the need to understand to love al-Quran has must be introduced make tradition by read a good. The especially learning student elementary school in SDIT under the auspices of Yayasan al-Aqsho Pesantren Hidayatullah Kudus. Data of this paper are gathered through literature, interview and observation which then analyzed in descriptive qualitative method. Al-Aqsha Hidayatullah Foundation is unique for its role play learning inquiri, project, problem based learning, and discovery learning. The model's, to combined three models learning, visual, auditory, and kinetic. The ekstrakulikuler covers qiroah, kaligrafi, scout, archery, piano and choir, tambourine, pencak silat, jurnalistic, dan coloring art. Expected figure straight akidah, morality Quran, the spirit of worships, for intellectual and intelegents qolbu. Motto, heart open by integral education and tauhid basic. The reality, realy etic generation, get used to read al-Quran and memorize. This institution supported character education.
\end{abstract}

Keywords: Hidayatullah, al-Quran generation, and morality.

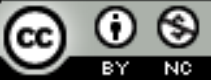

This work is licensed under a Creative Commons Attribution-NonCommercial 4.0 International 


\section{PENDAHULUAN}

Presiden Jokowi dan Wapres Ma'ruf Amin mencanangkan tujuh agenda pembangunan dalam Rencana Program Jangka Menengah (RPJMN) 2020-2024. Ketujuhnya (1) memperkuat ketahanan ekonomi untuk pertumbuhan yang berkualitas, (2) mengembangkan wilayah untuk mengurangi kesenjangan, (3) meningkatkan sumber daya manusia yang berkualitas dan berdaya saing, (4) revolusi mental dan pembangunan kebudayaan, (5) memperkuat infrastruktur mendukung pengembangan ekonomi dan pelayanan dasar, (6) membangun lingkungan hidup, meningkatkan ketahanan bencana dan perubahan iklim, dan (7) memperkuat stabilitas politik, hukum, pertahanan dan keamanan (polhukhankam) dan transformasi pelayanan publik. Pada poin 3 meningkatkan SDM yang berkualitas dan berdaya saing terwujud dengan pembangunan manusia Indonesia sejak belia. Konsekuensinya, lembaga pendidikan dasar harus mendapatkan perhatian dari negara secara proporsional dengan mengevaluasi pelaksanaan program wajib belajar (wajar). Masyarakat pun harus berpartisipasi mewujudkannya.

Era multimedia menandai mudahnya warga mengakses informasi tiap detik. Hal ini mempengaruhi kehidupannya menjadi dinamis dengan memanfaatkan media informasi teknologi (IT). Hanya saja, bagi individu yang tidak mampu memenuhi kebutuhan hidupnya dilampiaskan dengan cara yang keluar dari syariat Islam. Banyaknya tindak kriminal dan perdukunan di tengah masyarakat yang juga aktif beribadah. Menyikapi fakta tersebut, lembaga pendidikan dituntut memosisikan diri sebagai wahana menanamkan akidah yang benar dengan dasar al-Quran, al-Hadis, Ijmak, dan qiyas dengan dasar ilmu.

Naskah ini mengkaji pendidikan formal jenjang sekolah dasar (SD), bukan madrasah ibtidaiyah (MI) tetapi memiliki kekhasan yang perlu didalami karena memiliki kemiripan dengan muatan pelajaran dengan MI. Pola yang dilakukan dengan mengemas kurikulum integratif. Keterpaduannya diimbangi dengan nama jenjang pendidikan yakni Sekolah Dasar Islam Terpadu (SDIT). Obsesinya, "berkarakter djitu", maksudnya disiplin, jujur, Islam, tekun, dan unggul". Lembaga Pendidikan Hidayatullah juga tertebar di berbagai daerah termasuk di Kudus. Lembaga ini yang dikaji karena, pertama, ada anggapan sepihak dari publik yang tidak memahami realita pengelolaan manajemen pendidikan Hidayatullah, hanya melihat sekilas penampilan (tatacara berpakaian) siswa dan guru seperti bercelana cingkrang, bergamis, berjenggot seakan-akan condong pada gerakan Islam tertentu. Anggapan itu perlu diluruskan bahwa pakaian tersebut tidak melanggar syariat Islam, hukum positif, dan norma susila. Perilakunya pun tidak ada unsur radikalisme sehingga kecurigaan tidak perlu terjadi. Kedua, dikesankan oleh warga non-Hidayatullah bahwa Hidayatullah eksklusif. Hal ini pun tidak benar karena Masjid Hidayatullah di kompleks lembaga pendidikannya terbuka untuk umum dan menerima secara terbuka calon siswa dari semua strata dan lintas aliran. Ketiga, pemandangan umum terlihat di kompleks lembaga Hidayatullah bahwa anak-anak terbiasa membawa al-Quran dan membacanya setiap jengkal waktu, selain pembelajaran di kelas. Kondisi ini kontra dengan praduga publik di atas. Keempat, lembaga pendidikan formal Hidayatullah menaati kurikulum nasional, sebagaimana kurikulum lembaga lain. Hanya saja memiliki kekhasan, sebagaimana kajian naskah ini. Apa pun wujudnya lembaga pendidikan Hidayatullah ikut berperan nyata membangun SDM bangsa Indonesia di tengah kondisi pendikan nasional memerluka peran swasta.

Dinamisnya lembaga Hidayatullah, para peneliti menelaahnya dengan ragam kajian. Pertama, Dianto, peran Lembaga Amil Zakat Nasional Baitul Maal Hidayatullah Tulungagung Jawa Timur. Kinerjanya berpijak pada empat hal, pemberian wakaf alquran, beasiswa pendidikan, pembangunan masjid, santunan fakir dan bantuan ternak lele dan kambing (Dianto, 2014). Kedua, Zein, Ponpes Hidayatullah didirikan atas dasar semangat berdakwah untuk perbaikan muslim Indonesia dengan menekankan kaderisasi pendakwah. Ponpes Hidayatullah di Yogyakarta rintisannya dengan mendirikan panti asuhan, lembaga pendidikan (kelompok bermain, TK, hingga 
SMA), program dakwah (taman pendidikan alquran, majelis taklim, dakwah radio, pos dai), dan lembaga sosial (panti asuhan, SAR, dan baitul mal hidayatullah/BMH). Kegiatan segmen tersebut terpadu dengan dibentuknya yayasan (Zein, 2018).

Ketiga, Rukah, peran Baitul Maal Hidayatullah mengoptimalkan zakat pada program Senyum Anak Indonesia dengan pemberian beasiswa santri (via wali santri) di Ponpes al-Burhan Hidayatullah Desa Gedawang, Kecamatan Banyumanik, Kota Semarang, Jawa Tengah. Beasiswa disertai kesepakatan bahwa penerimanya (mustahiq) pascalulus mengabdi setahun di lembaga Hidayatullah. Upaya amil dengan menghimpun, mengelola, dan menentukan mustahiq dan mengawasi potensi mustahiq dan berinovasi mendayagunakan zakat. Dampak positif bagi mustahiq mampu lulus atas fasilitas Baitul Maal Hidayatullah (Rukah, 2019). Para peneliti menelaah aspek lembaga keuangan Hidayatullah dan dinamika lembaga pendidikannya di Yogya, naskah ini mengkaji ciri khusus pengelolaan lembaga pendidikan sekolah dasar Hidayatullah di Kudus Jawa Tengah. Jadi, naskah ini memiliki aspek kebaruan sehingga perlu didalami.

Permasalahan penelitian ini bagaimana dinamika lembaga Hidayatullah di Kudus dan apa saja upaya mengenalkan peserta didik agar mencintai al-Quran? Bagaimana penanaman pendidikan karakternya mewujudkan generasi qurani? Naskah ini ditulis bertujuan mengetahui dinamika lembaga Hidayatullah di Kota Kudus, apa saja upayanya agar anak didik menjadi generasi yang mengamalkan Islam sesuai alQuran, dan seperti apa pelaksanaan pendidikan karakternya. Hal ini akan mengilhami upaya untuk meniru aspek muatan pembelajaran yang didesain oleh pengelolanya sehingga memiliki jiwa yang mampu menjalankan syariat Islam dengan benar, terjauhkan dari perilaku syirik (tidak musyrik). Dipilihnya lembaga Hidayatullah sebagai obyek riset karena program integrasi pembelajaran Islam plus, yakni mengader siswa menjadi mubaligh dengan bekal pendidikan integratifnya.

Teori yang digunakan dalam naskah ini yakni anggaran pendidikan dan konsep pendidikan karakter. Ragam problem pendidikan nasional beserta dinamikanya perlu merujuk pelaksanaan pengangggaran pendidikan secara nasional khususnya pada tahun 2014 yang menjadi polemik. Pertama, pada Konvensi Pendidikan PGRI di Jakarta pada Rabu, 19 Februari 2014 mengemuka bahwa anggaran pendidikan nasional (sebagaimana amanat UU Nomor 20 Tahun 2003 tentang Sisdiknas) sebesar 20 persen dari APBN/APBD. Anggaran ini dianggap tidak efektif karena dibagi pada 18 institusi tidak hanya Kemenag dan Kemendikbud yang menyelenggarakan fungsi pendidikan. APBN 2014 sebesar Rp 1.842 triliun, anggaran pendidikan dipatok 20 persen sesuai konstitusi. Pos belanja pemerintah pusat tersebar di 18 kementerian/lembaga dengan total Rp 130,28 triliun. Alokasi terbesar pada Kemendikbud Rp 80,6 triliun, Kemenag Rp 42,5 triliun, sisanya di 16 kementerian/lembaga lainnya sebesar $\mathrm{Rp} \mathrm{7,05} \mathrm{triliun.}$

Sementara itu, lebih dari separuh anggaran pendidikan yakni $\mathrm{Rp} 238,6$ triliun justru dialokasikan ke daerah melalui pos transfer daerah. Anggaran pendidikan sebagian besar digunakan untuk gaji dan tunjangan guru. Total anggaran fungsi pendidikan tahun 2014 sebesar Rp 368,9 triliun, sebagian besar yakni Rp 238,6 triliun (64,7 persen) ditransfer ke daerah. Anggaran Kemendikbud hanya Rp 80,6 triliun, anggaran Kemenag $\mathrm{Rp} 42,5$ triliun, dan di kementerian/lembaga lain $\mathrm{Rp} 7$ triliun. Anggaran fungsi pendidikan berdasarkan UU Nomor 20 Tahun 2003 sebesar 20 persen di Kemendikbud di dalamnya digunakan untuk gaji dosen, guru, tunjangan profesi non-PNS, tunjangan khusus bagi guru di daerah khusus, dan tunjangan fungsional guru non-PNS yang belum mendapat sertifikasi. Dengan demikian, anggaran untuk biaya pendidikan selain gaji dan tunjangan di atas sangat minim. Gaji guru diberikan pemda dari pemerintah pusat dalam pemanfaatan dana alokasi umum (DAU).

Transfer dana pendidikan dari pusat ke daerah meliputi perkiraan dari dana bagi hasil $(\mathrm{DBH})$, dana alokasi khusus (DAK) pendidikan, perkiraan dari DAU, tambahan penghasilan guru PNS daerah, tunjangan profesi guru, perkiraan dari otonomi khusus, dana insentif daerah (DID), dana percepatan pembangunan infrastruktur pendidikan, biaya operasional 
sekolah (BOS), dana percepatan pembangunan infrastruktur daerah (DPPID) pendidikan. Total DAU pada APBN 2014 sebesar Rp 135 triliun, di tengah minimnya komitmen pemda (Harian Kompas, 3 Mei 2014). Kedua, Kemdikbud akan memperketat pendirian dan pengelolaan sekolah internasional karena banyak sekolah berlabel internasional yang melanggar dan beberapa tidak berizin. Data Kemendikbud, tercatat 110 sekolah internasional di Indonesia sebagian besar berada di Ibu Kota. Sekolah tersebut awalnya hanya untuk anak diplomat. Berdasarkan PP Nomor 17 Tahun 2010 tentang Pengelolaan Pendidikan, perwakilan lembaga asing yang menyelenggarakan satuan pendidikan tanpa ada kerja sama dengan satuan pendidikan Indonesia dilarang menerima siswa berkewarganegaraan Indonesia.

Beberapa sekolah tersebut tidak menyampaikan pendidikan kewarganegaraan, sejarah Indonesia, pendidikan agama, dan Bahasa Indonesia (Harian Kompas, 19 Maret 2014). Ketiga, Kemendikbud berupaya menggenjot angka partisipasi kasar (APK) perguruan tinggi (PT). APK PT adalah persentase warga negara usia 19 s.d 23 tahun telah mengakses pendidikan tinggi. Kemendikbud menargetkan pada 2015 APK PT mencapai 35 persen. Ekspansi kapasitas/daya tampung PT dan pembukaan PT baru menjadi andalan dalam meningkatkan APK PT. Daya tampung PT 2014 ditambah 20 persen dan PTN harus mengalokasikan minimal 20 persen untuk anak miskin. Pada 2004 APK PT 14 persen artinya ada 86 persen anak dari kelompok usia 19 s.d 23 tahun yang tidak mengenyam bangku perkuliahan. Pada 2012 APK 28 persen dan pada 2013 APK PT 30 persen. Hal yang perlu dievaluasi ulang adalah perihal memperketat pendirian dan pengelolaan sekolah internasional karena banyak sekolah berlabel internasional. Menjamurnya lembaga tersebut sebagai pesaing baru yang tidak kasat mata bagi pendidikan swasta di negeri sendiri.

Pendidikan karakter. Menurut Koesoema, bila pendidikan memadukan semua aspek pendidikan di dalam dan di luar sekolah. Bentukan karakternya berupa tanggung jawab, berdaya juang, cintai kebenaran, pemberani, dan menghargai perbedaan (Koesoema, 2016). Pada jangka panjang, pendidikan karakter bertujuan mengenalkan nilai secara kognitif, penghayatan secara efektif, dan mengamalkan nilai. Prinsip dasarnya terwujudnya fungsi dan tujuan pendidikan yakni kemampuan dan pembentuk watak yang bermartabat untuk kecerdasan anak bangsa, berkembangnya potensi iman dan takwa, berakhlak mulia, sehat, berilmu, cakap, kreatif, mandiri, demokratis, dan bertanggung jawab (Pasal 3 UU Nomor 20 Tahun 2003 tentang Sisdiknas). Hal ini merupakan tujuan pendidikan nasional secara luas, secara praktis yakni pembentuk diri menjadi baik dan cerdas (good and smart) dalam perilaku dan berpikir cerdas.

Jadi, keberhasilan pendidikan karakter adalah kemampuan mengader anak didik menjadi baik perilakunya dan kualitas pemikirannya. Wujud keberhasilannya bila menyatu antara suasana keluarganya, lembaga pendidikannya, dan masyarakatnya. Pendidikan karakter merupakan seluruh aspek pendidikan atau pebimbingan pada siswa supaya sadar atas nilai yang benar, baik, dan indah dengan proses yang tepat dan konsisten dalam membiasakan dalam bertindak. Tujuan pendidikan karakter pembentuk pribadi yang utuh, berkarakter dalam seluruh praktik pendidikan di sekolah berbentuk kurikulum, ekstrakurikuler, dan upaya lainnya. Hal ini mencakup nilai (value) agama, nilai budaya, nilai etika, dan nilai estetika menuju terbentuknya pribadi cerdas keagamaan, pengendali diri, berkepribadian utuh, berakhlak mulia, dan terampil. Adapun misi pendidikan karakter/nilai (1) membina peserta didik agar memahami dan menyadari karakter nilai diri dan orang lain, (2) berakhlakul karimah dan melakukan pembelajaran yang berproses pembinaan karakter/nilai dengan pendekatan menyeluruh, membantu anak didik agar paham, sadar, dan memahami nilai dan mumpuni menempatkan secara padu dalam hidupnya (Sauri dan Hufad, 2007:41).

Fungsi pendidikan karakter berupa (1) seleksi terhadap nilai yang terdapat dalam filsafat yang menempatkan ahli pendidikan karakter untuk menata kerangka berpikir filosofis agar terartikulasikannya nilai unggul, (2) menyeleksi atas nilai dalam ilmu pengetahuan yang menempatkan ahli pendidikan karakter/nilai agar selalu mencermati dan 
mengkaji perkembangan ilmu pengetahuan yang berimplikasi pada ilmu pengetahuan, dan (3) menyeleksi atas nilai dalam teori pendidikan yang menempatkan ahli dan praktisi pendidikan nilai untuk mencermati dan memilih teori pendidikan yang sesuai kebutuhan agar menjadi diri berjati diri.

Pendidikan karakter lahir karena pendidikan masih memfokuskan pada kecerdasan akademik dengan ukuran nilai (angka) dan kelulusan yang bersifat numerik. Tingginya angka tidak menjamin anak didik mampu menjadi ilmuwan yang memegang etika dan sukses dalam bersosialisasi. Unsur karakter dalam pendidikan karakter meliputi religiositas, jujur, toleran, disiplin, cinta kedamaian, bertanggung jawab, peduli sesama dan ramah lingkungan, kreatif, gemar membaca, pembiasaan dan ketauladanan melalui budaya sekolah, pembiasaan di rumah, dan kegiatan kurikuler, kokulikuler, dan ekstrakulikuler.

Ekstrakulikuler meliputi berupa kepanduan, karya tulis, olahraga, pendalaman praktek beragama seperti pemahaman toleransi beragama dan bersuku, ras, mencintai lingkungan fisik dan nonfisik, dsb. Unsur-unsur itu termaktub pada ranah afektif (pemikiran/pembelajaran) dan psikomotorik (praktik kehidupan) disertai evaluasi melekat dan berkesinambungan. Analisa Bagir, janganlah niat baik pengembangan pendidikan karakter dan moral dirancang untuk mendorong semangat kesalehan anak didik yang salah penempatan (misplaced pietism), salah penggunaan (misused) yang melahirkan perilaku yang bertentangan dengan tujuan pendidikan karakter (Baqir, 2013:6).

Menurut Pawitasari ada enam prinsip pendidikan karakter islam (1) menjadikan Tuhan sebagai tujuan, (2) memperhatikan akal/rasio, (3) memperhatikan perkembangan kecerdasan emosi, (4) praktik melalui keteladanan dan pembiasaan, (5) memperhatikan pemenuhan kebutuhan hidup, dan (6) memprioritaskan nilai (Pawitasari, 2013:23). Ada tiga matra pendidikan karakter, yakni individu, sosial, dan moral yang merupakan kesatuan matra dalam memberi perhatian pada perkembangan anak dengan mengukuhkan diri sebagai makhluk bermoral, membuat pendidikan karakter memiliki fungsi pedagogis. Visi pendidikan karakter adalah cita-cita menuju kinerja lembaga pendidikan. Bila peserta didik dilibatkan maka jiwa pendidikan karakter merupakan bagian keyakinan diri anak didik dan komunitas lembaga pendidikan (Koesoema, 2007:145 dan 156).

Adapun dimensi pendidikan karakter adalah pendidikan nilai dan pendidikan moral. Nilai adalah suatu kualitas yang menjadikan suatu itu disukai, diinginkan, dan dihargai dan menjadi obyek bagi kepentingan tertentu. Pendidikan moral menjadi dasar pendidikan karakter. Pendidikan moral sebagai usaha individu untuk membentuk dan mengafirmasi diri dan menjadi pribadi bermoral. Moral merupakan pemahaman atas nilai dan norma yang menjadi pegangan bagi individu dalam komunitas agar kebebasan dan keunikan tiap diri tak dilanggar sehingga menghargai martabat masing-masing. Ada pembeda antara pendidikan karakter dengan pendidikan moral, pendidikan moral ruang lingkupnya kondisi batin individu untuk sadar diri.

Adapun pendidikan karakter bertujuan menegakkan martabat manusia sebagai individu (Koesoema, 2007:195). Dimensi sosial pendidikan karakter, terciptanya sistem sosial yang kondusif bagi pertumbuhan pribadi. Adapun basis pendidikan karakter yakni kelas, kultur sekolah, dan komunitas. Aspek yang perlu dievaluasi dalam pendidikan karakter (1) menemukan momen pembentuk karakter pada saat pembelajaran, (2) ekstrakuler dapatkah mengembangkan keterampilan, minat, bakat dan kemampuan di bidang olahraga, seni, budaya, kelompok diskusi, jurnalistik, dan peminatan bakat lainnya, dan (3) sejauhmana kolaborasi antara sekolah dan rumah, lembaga pendidikan dan masyarakat sekitar lembaga pendidikan (Koesoema, 2016:6).

\section{METODE PENELITIAN}

Artikel ini merupakan hasil riset penulis tahun 2020 data diperoleh dengan wawancara, observasi, dan kajian pustaka. Wawancara dilakukan dengan pengelola lembaga pendidikan Hidayatullah dan observasi di lembaga Hidayatullah Kudus. Data dianalisis dengan 
pendekatan deskriptif kualitatif. Riset ini kategori field riserch (penelitian berbasis lokasi/lapangan). Tahapan untuk mendapatkan data dengan (1) studi prariset menelaah literatur seputar dinamika pendidikan dan pendidikan Hidayatullah, (2) survei pendahuluan untuk mengetahui kondisi umum lembaga pendidikan Hidayatullah di Kudus, (3) survei lapangan dan pengumpulan data dengan observasi, wawancara, literatur dan dokumentasi, (4) menyusun sistematika penulisan untuk bahasan obyek kajian di bab pembahasan, dan (5) diakhiri dengan simpulan dan daftar pustaka.

\section{TEMUAN DAN PEMBAHASAN}

\section{Temuan}

Lembaga Pendidikan Hidayatullah di Kota Kudus memiliki keunggulan yakni siswa ditradisikan membaca al-Quran setiap hari, salat wajib dan sunah, dan menghapalkan minimal 3 juz bila akan menamatkan SD. Model pembelajarannya inquiri, project, and problem based learning, dan discovery learning dipadu dalam tiga gaya belajar yakni visual (melihat), auditory (mendengar), dan kinetic (gerak). Qiroah (membaca al-Quran dengan merdu), tilawah (membaca al-Quran dengan fasih), kaligrafi (seni menulis huruf Arab), pramuka, panahan, pianika, paduan suara, rebana, beladiri, jurnalistik, dan seni mewarnai merupakan ragam ekstrakulikulernya.

Keberhasilannya sesuai Piagam Gunung Tembak (Piagam Hidayatullah) (1) membangun peradaban Islam sebagai jihad, (2) pusat peradabannya masjid, tiap kader wajib menjadikannya pusat ibadah, pengembangan keilmuan dan karakteristik kepemimpinan, (3) tiap kader wajib salat wajib, salat nawafil terutama qiyamul lail, membaca al-Quran, dan beribadah lainnya, (4) tiap kader merupakan generasi Rabbani yakni diwajibkan menghidupkan majlis ilmu, membangun tradisi keilmuan dan berdakwah dan berhalaqoh (berdiskusi) sebagai media transformasi keilmuan, karakter diri dan sosial, (5) peduli, gemar menolong dan berkurban, tawadluk, militan, qona'ah, dan mengutamakan kehidupan akhirat, dan (6) tiap pemimpin dan kader diwajibkan menjadi tauladan bagi umat dengan solidaritas jamaah dan persaudaraan/ukhuwah.

\section{Pembahasan}

\section{Awal Mula Lembaga Hidayatullah}

Nama 'Hidayatullah' yang melekat pada Lembaga Hidayatullah dikesankan bahwa lembaga tersebut atas prakarsa seseorang yang bernama Hidayatullah, padahal bukan. Tujuan pemberian nama 'hidayatullah' agar guru/ustad, peserta didik, penyelenggara pendidikannya selalu mendapat petunjuk/hidayah dari Allah SWT. Lembaga Hidayatullah dideklarasikan oleh Abdullah Said. Sang ayahandanya, Abdullah Kahar Syuaib menikah sebanyak tiga kali karena sang isteri pertama meninggal, kawin kedua, isteri kedua meninggal, kawi ketiga, bukan poligami.

Perkawinan pertama dengan Nafisah dikaruniai 2 putra, Asiyah Kahar (wafat saat berusia 3 tahun) dan Muhammad Djamil Kahar (Puang Milu). Isteri keduanya Bunyamin (Puang Bune) dikaruniai 6 putra, Zubair Kahar (Puang Bere'), Juhaefah Kahar (Puang Efah), Radhiyah Kahar (Puang Radi), Maryam Kahar (Puang Mari'), Hamdanah Kahar (Puang 'Ndah), Siti Zulaikhah Kahar (Puang Itti). Isteri ketiganya, Aisyah (Puang Ica) dikaruniai 4 putra, yakni Junaid Kahar (Puang Juna), Lukmanul Hakim (Puang Luke), Muhsin Kahar (Puang Esseng), As'ad Kahar (Puang Sade). Muhsin Kahar diganti namanya menjadi Abdullah Said, sang pendiri Hidayatullah. Perubahan nama akibat ketika muda, Abduulah Kahar pada 28 Agustus 1969 menjadi buronan aparat kepolisian karena membubarkan judi. Tatkala usia kandungan ibu Aisyah berusia 2 tahun, sang jabang bayi belum pula lahir. Akhirnya sang bayi (Muhsin Kahar atau Abdullah Said) lahir pada 17 Agustus 1945 di Kampung Lamatti, (dijuluki Kampung Panreng maknanya kuburan karena suasana kampung saat itu berbeda dengan kampung lain yakni terkesan seram (Salbu, 2009).

Muhsin Kahar atau Abdullah Said tahun 1952-1955 belajar di Sekolah Rakyat (SR) hanya di kelas 3 karena keluarganya pindah ke Makassar akibat saudara kandung sebapak Muhsin Kahar (Zubair Kahar) diduga ada persoalan hingga diinterogasi aparat. Sang ayah tatkala di rantau dipercaya warganya menjadi 
Imam Masjid Lailatul Qodri dan pendakwah di Kampung Malimongan Baru (kini di Jalan Pong Tiku) Makassar. Abdullah Said belajar lagi melanjutkan di Sekolah Rakyat/SR (kini sekolah dasar/SD) pada kelas 4 hingga tahun 1958. Said melanjutkan belajar Pendidikan Guru Agama Negeri (PGAN) selama 6 tahun di Kota Makassar dan kuliah di IAIN Alauddin Makassar (kini Universitas Islam Negeri Alauddin Makassar) tetapi hanya semester dua. Said sempat aktif di lembaga Pemuda Pelajar Islam (PPI), dan Pemuda Muhammadiyah.

Di PPI, Muhsin bergabung pada tahun 1965 dan bergabung pula di Pemuda Pelajar Kesatuan Aksi Pemuda dan Pelajar Indonesia (KAPPI) Sulawesi Selatan dan Himpunan Pemuda Pelajar Mahasiswa Sinjai (HIPPMAS). Adapun di lembaga Pemuda Muhammadiyah yang berada di Malimongan Baru Makassar, Muhsin duduk di jajaran pengurus wilayah Sulawesi Selatan dan Tenggara (Sulselra) periode 1966-1968 sebagai Ketua Biro Dakwah dan Publikasi. Untuk menambah ilmu keislaman, Said mengaji di Pondok Pesantren Gontor Ponorogo Jawa Timur dan di Pondok Pesantren Persis Bangil, Jawa Timur. Sepulang dari nyantri di Jawa Timur, Said mendirikan pondok pesantren, hanya saja karena usianya terlalu muda, 20 tahun, keluarganya tidak mendukung karena diduga tidak siap secara psikis. Tahun 1972 Said pindah ke Balikpapan mendirikan Ponpes Hidayatullah hingga kini eksis di berbagai daerah.

Tahun 2013 ada 33 Dewan Pimpinan Wilayah (DPW) tingkat provinsi, 287 Dewan Pimpinan Daerah (DPD) tingkat kab/kota, dan 70 Pimpinan Cabang (PC), Pimpinan Ranting (PR), dan Pimpinan Anak Ranting (PAR). Upayanya dikembangkan dengan mendirikan Sekolah Tinggi Ilmu Ekonomi Hidayatullah (STIEHid) di Depok, Jawa Barat, Sekolah Tinggi Agama Islam (STAI) Luqman Al-Hakim di Surabaya, Jawa Timur, dan Sekolah Tinggi Ilmu Syariah (STISID) di Balikpapan. Didirikan pula lembaga sosial berupa pusat pendidikan anak saleh (PAS) yakni peserta didik anak yatim, piatu, atau yatim-piatu yang diasramakan. Ada pula bidang dakwah, yakni Hidayatullah Training Center. Jenjang pendidikannya sejak Taman Kanak-Kanak dan Kelompok Belajar
(KB), SD/MI, SMP/MTs, SMA/MA, SMK, dan 3 perguruan tinggi.

Dinamika organisasi dialami Hidayatullah, pada musyawarah nasional yang pertama tanggal 9 s.d 13 Juli 2000 diputuskan Hidayatullah menjadi organisasi sosial kemasyarakatan (Ormas) dan sebagai gerakan dakwah dan perjuangan Islam yang dasar gerakannya bersifat terbuka dan purifikasi ajaran Islam. Menurut Qodir, strategi gerakan sosial keagamaan ada empat model, (1) menghindar dari interaksi dengan pemerintah (isolasi politik), pemberdayaan dan transformasi sosial, advokasi hukum, dan mengkritisi kebijakan pemerintah (Qodir, 2014:23).

Hidayatullah lebih memilih pemberdayaan sosial di bidang dakwah dan pendidikan dan memfokuskan pada kecintaan al-Quran daripada mengkaji ilmu fikih (fikih pun dikaji) yang dianggapnya sumber polemik intern-umat Islam dan bila tidak mewaspadai akan meruncing menjadi konflik karena kurang dewasanya menyikapi perbedaan pandangan dalam fikih. Menurut Jainuri, ada empat orientasi ideologi gerakan Islam, yakni tradisionalis (gerakan Islam tradisional), modernis (gerakan Islam modern), sekularis, dan fundamentalis (Jainuri, 2004:57). Hidayatullah berorientasi modernis dan bersifat pemberdayan dan transformasi sosial untuk kemaslahatan bangsa. Hal ini dibuktikan dengan hadirnya pendakwah hasil didikannya di Nusantara, khususnya wilayah yang masih minim keislamannya.

\section{Embrio dan Dinamika Hidayatullah di Kudus}

Di Kota Kudus lembaga Hidayatullah eksis sejak tahun 1992. Pada awalnya model mengaji al-Quran secara tradisional oleh tenaga dakwah Hidayatullah dari Surabaya ditugaskan khusus mengembangkan visi-misi Hidayatullah yakni Imam Syahid. Pemuda ini bersama dua teman lajangnya, Abdurrahman dan Fatih (kini di Ponpes Hidayatullah Surabaya). Kedatangannya di Kudus berbekal Majalah Hidayatullah untuk dijual sekaligus sosialisasi majalah dan hasilnya untuk biaya hidupnya. Kedatangannya di Kudus membawa alamat orang di Kudus yang dituju, yakni seorang notaris, Sulkan Abdul Malik. Akan tetapi, sang notaris kurang merespon 
program Hidayatullah. Selanjutnya ke Desa Tahunan Jepara menjumpai seseorang untuk kepentingan menyosialisasikan program Hidayatullah. Tetapi, Imam merasakan tidak mendapat respon pula sehingga kembali ke Kudus menjumpai Sonhaji di Desa Ploso.

Saat itu, ia direspon dan diberi kesempatan untuk singgah di rumahnya selama dua minggu. Dari rumah Sonhaji, Imam bersama dua temannya mendapat informasi bahwa ada calon muwakif (orang yang akan mewakafkan tanah) untuk dakwah. Imam menemui Abdul Malik (diduga calon muwakif) akan tetapi hasilnya belum sesuai harapan. Mereka kembali ke Surabaya untuk menginformasikan kondisi di Kudus yakni upaya mendapatkan muwakif yang belum berhasil. Pada tahap berikutnya setelah kembali ke Kudus lagi, Imam berencana mengontrak rumah sementara sembari mencari info calon muwakif. Harga/biaya kontrak setahun $\mathrm{Rp} 500$ ribu.

Rencana ini diinformasikan pada Pimpinan Hidayatullah Surabaya. Akan tetapi, ditolak dan disarankan sang kiai Hidayatullah untuk kembali ke Kudus tanpa mengontrak dan tidak kembali ke Hidayatullah Surabaya sebelum berhasil mendapatkan muwakif untuk lembaga Hidayatullah di Kudus. Imam optimis upayanya berhasil dan ia berjanji tidak kembali ke Surabaya sebelum sukses di Kudus dengan mengembangkan Hidayatullah.

Setiba di Kudus agar biaya hidup murah Imam melakukan dengan menjadi santri dan hidup di Pondok Pesantren di Kampung Kauman Menara Kudus. Ia memanfaatkan sepeda ontel yang dibelinya sumber dana dari kiriman teman Hidayatullah untuk mencari info pewakaf tanah dan untuk menjual Majalah Hidayatullah keliling antar-kampung. Per eksemplar Majalah Hidayatullah seharga Rp 1.500 yang hasilnya untuk biaya hidup di Kudus. Perkembangannya, Imam bertemu Widodo memberi info bahwa Kiai Kurtubi mendapat kabar bahwa ada orang yang akan mewakafkan tanah. Imam menemui Kurtubi, orang yang dimaksud calon muwakifnya adalah Sumiyadi. Imam menemui Sumiyadi untuk menyampaikan tujuannya mengembangkan Hidayatullah di Kudus. Imam diberi kesempatan menempati rumah Sumiyadi di belakang Masjid Al-Makruf (dekat Pasar
Kliwon) Desa Rendeng, Kecamatan Kota selama dua tahun. Di rumah itulah dioptimalkannya sebagai tempat mengaji al-Quran bagi warga sekitar yang berminat (cikal bakal pondok pesantren). Guru mengaji memanfaatkan lima mahasiswa dari Fakultas Ushuluddin IAIN Walisongo Semarang di Kudus (kini bernama IAIN Kudus). Berkumpulnya orang dan anak yang mengaji ada warga setempat yang mencurigai sehingga ia berkirim surat kaleng pada Imam. Isi surat agar dibentuk kepengurusan mengaji dan mengultimatum bila tidak terbentuk diusir dari rumah tersebut. Sikap Imam, mengadakan temu warga di sekitarnya dengan calon pengurus pesantren. Pembentukan kepengurusan pesantren terdiri para guru yang menjadi ustad di ponpes tersebut.

Sumiyadi (muwakif) mewakafkan rumah yang selama ini digunakan mengaji warga sekitar tetapi tidak optimal di Dukuh Grogol, Desa Bakalan Krapyak, Kecamatan Kaliwungu. Pada tahun 1992 rumah tersebut dimanfaatkan Imam untuk tempat mengaji al-Quran yang santrinya berjumlah 30 santri dari berbagai daerah dengan pola informasi nonformal antarwarga Hidayatullah. Pada tahun 1993 wakaf yang dilakukan Sumiyadi secara resmi diterima lembaga Hidayatullah yang diterima melaui Imam Syahid. Tanah wakaf tersebut hingga kini sebagai sentral kegiatan pendidikan formal dan nonformal. Pada fase berikutnya, Hidayatullah menerima tanah wakaf dari H. Mas'an di Desa Kedungdowo, Kecamatan Kaliwungu, Kudus. Kini, tanah wakaf untuk Kantor DPD Hidayatullah Kudus, sekolah, asrama, dan boarding school hanya putra, dan masjid Hidayatullah.

Pada perkembangannya, Lembaga pendidikan formal Hidayatullah terdiri Kelompok Bermain (KB) dan Taman KanakKanak Ya Bunayya berdiri 2002, SDIT Luqman Al-Hakim sejak 2001, SMP Islam Integratif Putri sejak 2004, SMP Islam Integratif Putra sejak 2010, SMK Hidayatullah Putra bidang jaringan komputer sejak 2015. Untuk KB, TK, SD, dan SMP putri di Kampung Grogol Loji, Desa Bakalan Krapyak. Untuk SMP putra dan SMK putra di Jl.Raya Kudus-Jepara KM.5 Desa Kedungdowo, Kecamatan Kaliwungu. Perkembangan berikutnya, Hidayatullah 
mendirikan lembaga keuangan syariah yakni Baitul Mal Wat-Tamwil (BMT) Amanah (Sharia Micro Finance), dan Inova service dan jual beli printer komputer. BMT Amanah melayani simpanan dana, pembiayaan, jasa keuangan syariah berupa tagihan pembayaran PAM dan PLN, dan pembayaran zakat di Dukuh Grogol, Desa Bakalan Krapyak, Kantor cabangnya ada di Desa/Kecamatan Jati (Rosyid, 2019).

\section{Upaya Mengenalkan Anak Didik Cinta al- Quran sejak Usia Sekolah Dasar}

Hal yang menjadi pembeda antara pendidikan Hidayatullah dengan lembaga lain terletak pada semangat/spirit pendidiknya dalam pembelajaran. Bagi guru, proses pendidikannya adalah mempelajari Islam (islamic learning), bukan mempelajari tentang Islam (learning about Islam), apa bedanya? Belajar tentang Islam mengarah pada aspek teori/konsep keislaman, tetapi belajar Islam sebagai upaya mewujudkan ajaran Islam untuk kehidupan santri/siswanya. Karakter islami diwujudkan dengan kedisiplinan, kejujuran, dan berakhlak mulia dalam berbicara dan berperilaku tekun dan berprestasi unggul. Media yang digunakan sarana mewujudkan karakter itu dengan materi pembelajaran praktek ibadah salat wajib lima waktu berjamaah (bagi yang di asrama), mengkaji hadis, pendidikan agama Islam, praktek berbahasa Arab, halaqoh (pendampingan wali kelas pada anak didik dalam hal tilawah al-Quran. Bentuk tadarus alQuran meliputi adab membaca al-Quran, motivasi spiritual dan sosial, dan setiap hari ada mata pelajaran al-Quran dua jam pelajaran (belajar membaca dan menulis al-Quran) dan mapel tahfid (menghapal al-Quran). Hal ini dijadikan dasar mengenalkan al-Quran sejak di kelas 1 SDIT Luqman al Hakim Hidayatullah di Kudus. Pembelajaran mulai pukul 07.15 hingga 13.10 Wib (meski kelas 1 SD di SD lainnya pulangnya pukul 10.00 Wib) sedangkan pada Hari Jumat pulang pukul 11.00 Wib (pembelajaran pramasa pandemic covid-19).

Kurikulum yang digunakan disebut kurikulum integral karena mengintegrasikan nilai tauhid (keislaman) berupa al-quran, hadis, pendidikan agama Islam (PAI), praktek salat, dan halaqoh dengan kurikulum nasional yakni mapel tematik, bahasa Jawa, dan pendidikan jasmani dan olahraga kesehatan. Pengintegrasian agar anak kokoh akidahnya, ibadah dengan benar dalam berakhlak mulia. Nilai spiritualnya dengan ditumbuhkannya kepribadian yang jujur, berdisiplin, beribadah dengan taat, dan terbentuknya calon pemimpin yang amanah sebagai nilai spiritualnya. Tauladan dari ustad/guru merupakan pionir sejati sebagai modal siswa menauladaninya untuk pembentukan karakter. 
Jadwal Pelajaran SDIT Luqman al Hakim Kudus Kelas 1 Tahun Pelajaran 2019/2020 M

\begin{tabular}{|c|c|c|c|c|c|c|}
\hline Waktu & Senin & Selasa & Rabu & Kamis & Jumat & Sabtu \\
\hline $07.15-.50$ & Apel Motivasi & Tahfid & Tahfid & Tahfid & Tahfid & Tahfid \\
\hline $07.50-$ & & & & & & \\
\hline 08.25 & Al-Quran & Tematik & Al-Quran & PJOK & Tematik & Halaqoh \\
\hline $08.25-$ & 10 & & 10 & & 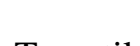 & \\
\hline 09.00 & Al-Quran & Tematik & Al-Quran & PJOK & Tematik & Al-Quran \\
\hline 09.35 & Tematik & Al-Quran & Tematik & Al-Quran & Transisi & Al-Ouran \\
\hline $09.35-$ & & & & & & \\
\hline 10.10 & Tematik & Al-Quran & Tematik & Al-Quran & PAI & Transisi \\
\hline $10.10-$ & T. & T. & $T_{0} \cdot$. & $T_{0} \cdot$. & $\mathrm{Du}$ & \\
\hline $\begin{array}{l}10.25 \\
10.25-\end{array}$ & Transisi & Transisi & Transisi & Transisi & PAI & Tematik \\
\hline 11.00 & Bahasa Arab & Bahasa Jawa & Tematik & Tematik & Pulang & Tematik \\
\hline $11.00-$ & & & & & & \\
\hline 11.35 & Bahasa Arab & Literasi & Tematik & Tematik & & Pulang \\
\hline $11.35-$ & & & & & & \\
\hline 12.35 & Ishoma & Ishoma & Ishoma & Ishoma & & \\
\hline $12.35-$ & . & & & & & \\
\hline 13.10 & Tematik & Hadis & Praktek ibadah & Tematik & & \\
\hline
\end{tabular}

Program unggulannya siswa ditradisikan membaca al-Quran setiap hari, salat wajib dan sunah, dan menghapalkan minimal 3 juz bila akan menamatkan SD. Hanya saja, karena usia masih belia, anak belum dibekali ilmu tajwid tetapi mengenalkan cinta pada al-Quran dan tertradisi membaca sebagai penanaman yang diutamakan. Hal ini membentuk karakter anak tertanam pada dirinya pendidikan nilai qurani. Keberhasilan pendidikan nilai menurut Zuchdi bila semua yang terkait dengan nilai dan etika terlaksana sesuai usia anak didik dengan tauladan dari pendidik, sejak di kelas yang dipraktekkan dalam kehidupan (Zuchdi, 2008:36). Aplikasi sosialnya bila anak hidup bersama masyarakatnya.

Inquiri, project, and problem based learning, dan discovery learning sebagai model pembelajarannya dipadu dalam tiga gaya belajar yakni visual (melihat), auditory (mendengar), dan kinetic (gerak). Qiroah (membaca al-Quran dengan merdu), tilawah (membaca al-Quran dengan fasih), kaligrafi (seni menulis huruf Arab), pramuka, panahan, pianika, paduan suara, rebana, beladiri, jurnalistik, dan seni mewarnai merupakan ragam ekstrakulikulernya. Aktifitas ekstrakulikuler tersebut yang peminatnya paling banyak adalah tilawah dan memanah, yang paling sedikit peminatnya paduan suara. Profil yang diharapkan lurus akidahnya, berakhlak alQuran, beribadah dengan berjamaah sebagai komitmennya untuk bekal mewujudkan kecerdasan qolbu. Kredonya, membuka hati dengan pendidikan integral berbasis tauhid.

Fasilitas ekstra berupa ruang kelas AC, musola, dan catering. Wali santri pun difasilitasi konsultasi perkembangan anak, kelas parenting, komunitas ayah bundaku, dan tersedia Majalah Islam Hidayatullah. Anak pun difasilitasi catering makan siang Rp 200.000 dan snack Rp 100.000 meskipun catering bukan wajib diikuti karena ada yang di asrama, ada yang tidak di asrama. Pembiayaan per siswa baru meliputi infak pengembangan lembaga Rp 4.000.000, pengembangan sarana pendidikan Rp 1.250.000, sumbangan buku perpustakaan Rp 50.000, raport Rp 200.000, praktik dan ekstrakulikuler $\mathrm{Rp}$ 400.000, seragam putra Rp 625.000, putri $R p$ 
900.000, Sumbangan Pembangunan Pendidikan Rp 225.000, infak kepramukaan Rp 10.000, kalender sekolah Rp 25.000. Jadi , biaya ratarata siswa Rp 7 juta-an sejak masuk pertama.

\section{Pendidikan Karakter Media Kaderisasi Generasi Qurani di Lembaga Hidayatullah di Kudus}

Kemampuan mewujudkan konsep pendidikan karakter menjadi generasi yang mencintai al-Quran (generasi qurani) merupakan tugas pokok yang dicanangkan lembaga pendidikan Hidayatullah di Kudus. Hal dasar yang harus dipahami bahwa faktor pembentuk kepribadian peserta didik memerlukan konsep pendidikan karakter dan pembelajaran demokratis yang direalisasikan dalam pembelajaran di kelas. Integrasi keduanya (pandidikan karakter dan pembelajaran demokratis) mewujudkan generasi qurani memerlukan dukungan tenaga kependidikan dan pendidik. Dengan demikian, keduanya memadu sebagai bekal menjadi generasi qurani yang dibekali karakter islami. Hal ini sebagaimana di SDIT Luqman al Hakim di bawah Yayasan al Aqsha Hidayatullah Kudus mempunyai kekhasan dengan ciri mampu membaca dan menghapal al-Quran sejak usia sekolah dasar. Hal tersebut diperkokoh dengan pendidikan berbasis pembelajaran demokratis yakni (1) memberi perlindungan terhadap anak didik untuk tidak melanggar hukum, mewujudkan kebebasan berpendapat, dibiasakan bermusyawarah dalam pembelajaran, memberi pemahaman dengan cara tidak memaksakan kehendak pendidik, menghormati perbedaan pendapat dalam proses pembelajaran, selalu memberikan motivasi kepada peserta didik yang belum siap menerima materi ajar atau yang belum memahami materi ajar oleh pendidik, memberikan kebebasan berekspresi dengan batasan tidak melanggar norma-norma agama, hukum, sosial, dan akademik. Hal ini melalui fasilitasi ekstrakulikuler, (2) pendidik menerapkan nilai humanis maksudnya pendidikan yang memanusiakan manusia dengan cara menyadari kekurangan dan kelebihan potensi yang dimiliki tiap individu, (3) mengaplikasikan ruh pendidikan yakni hubungan komunikatif antara peserta didik dengan pelaku pendidikan di saat (masih) aktif menjadi siswa atau telah lulus, (4) mengedepankan konsep pendidikan bermartabat yakni menghormati keberadaan peserta didik sebagai manusia yang berpotensi maju, berkembang, bahkan mundur dari sisi prestasi dan lainnya, (5) mewujudkan pendidikan multikultural yakni pendidikan yang menghormati perbedaan suku, ras, agama, dan kelompok. Hal yang perlu diwujudkan, kini belum direncanakan, yakni merealisasikan penghormatan karena beda agama. Selama ini, hanya berinteraksi dengan pihak yang seagama saja, (6) tidak mendiskriditkan, mengerdilkan, dan tidak berprasangka buruk terhadap potensi perempuan (tidak bias jender), (7) mengaktualisasikan pendidikan yang pluralis yakni menghormati peserta didik dan pelaku/penyelenggara pendidikan meskipun berbeda agama dan keyakinan, (8) pendidikan yang tidak melakukan kekerasan, baik kekerasan secara fisik atau pun psikis yang dilakukan oleh pendidik kepada peserta didik, peserta didik terhadap pendidik, penyelenggara pendidikan terhadap peserta didik atau pendidik, sedangkan kekerasan fisik seperti menampar, mencubit, dsb. Adapun kekerasan psikis seperti mendeskriditkan, mencemooh, dsb., dan (9) pendidikan yang mengedepankan nilai hak asasi manusia (HAM) meliputi hak-hak yang diturunkan Tuhan kepada hamba-Nya antara lain hak hidup, hak berpendapat, hak untuk pandai, hak beragama, dsb. Selain sembilan hal tersebut perlu pula pembelajaran yang mengedepankan perlindungan kemanusiaan.

Nilai-nilai humanis dan menaati azas HAM terwujud di Lembaga Hidayatullah karena (secara nasional merujuk Piagam Gunung Tembak/Piagam Hidayatullah). Piagam ini memuat (1) membangun peradaban Islam sebagai jihad tiap muslim, (2) pusat peradabannya adalah masjid, tiap kader wajib menjadikan masjid sebagai pusat ibadah, pengembangan keilmuan dan karakteristik kepemimpinan, (3) tiap kader wajib salat wajib di masjid, salat nawafil, terutama qiyamul lail, membaca al-Quran, dan beribadah sesuai ajaran Islam, (4) tiap kader merupakan generasi Rabbani yakni diwajibkan menghidupkan majlis ilmu, membangun tradisi keilmuan dan 
berdakwah. Dengan demikian, diwajibkan berhalaqoh (berdiskusi) sebagai media transformasi keilmuan, mentransformasikan karakter dan berkarakter sosial, (5) peduli, gemar menolong dan berkurban, tawadluk, militan, qona'ah, dan mengutamakan kehidupan akhirat, dan (6) tiap pemimpin dan kader wajib menjadi tauladan bagi umat dengan solidaritas jamaah dan persaudaraan/ukhuwah. Piagam tersebut ditandatangani oleh Abdurrahman Muhamad, Pemimpin Umum Hidayatullah, Hamim Thohari, Ketua Dewan Syuro, Abdullah Ihsan, Ketua Dewan Majelis Pertimbangan Pusat, dan Abdul Manan Ketua Umum mengesahkan Piagam pada 24 Juni 2013.

Upaya purifikasi ajaran Islam dan kekhasan berpakaian bagi sivitas akademika Hidayatullah rentan digosipkan oleh pihak tertentu yang tidak senang atas kemajuan lembaga pendidikan Islam dengan sebutan gerakan teroris. Anggapan ini perlu disikapi dengan mewujudkan pendidikan demokratis daan siswa dilibatkan membaur dengan ragam komunitas pada even tertentu agar menjadi semakin inklusif. Perlu diingat, Pascapengeboman World Trade Center AS (WTC) pada 11 September 2001, Amerika masih memunculkan kecurigaan terhadap warga muslim dunia. Hal ini diwujudkan dengan adanya program kontraterorisme (program melawan teroris). Kepolisian New York AS merekrut para imigran (sebagian besar muslim) untuk dijadikan informan yang memata-matai aktivitas di kafe, resto, dan masjid. Para imigran tersebut berprofesi sebagai penjual makanan keliling asal Afghanistan, sopir asal Mesir, dan pelajar asal Pakistan. Sebagian imigran yang dijadikan informan polisi Amerika ditangkap dalam kasus-kasus kecil seperti tiket parkir. Perekrutan detektif swasta itu sebagai upaya deteksi dini AS mengetahui pihak yang memberikan pandangan soal dunia terorisme (Harian Kompas,12 Mei 2014). Sidang Umum PBB di New York 23 September 2010, Presiden Iran saat itu Mahmud Ahmadinejad menegaskan teori konspirasi serangan teroris 11 September 2001 di New York dan Washington bahwa AS terlibat serangan atau membiarkan. Serangan untuk membalikkan kemenangan ekonomi AS dan pengaruhnya di Timur Tengah demi menyelamatkan rezim Zionis. Tatkala
Ahmadinejad berpidato pada Sidang Umum PBB di New York 11 September 2010 perwakilan AS, Inggris, Swedia, Australia, Belgia, Uruguay, dan Spanyol keluar dari ruang sidang (Obama berpidato pagi hari, Ahmadinejad sore harinya). Ahmadinejad meminta PBB membentuk tim pencari fakta independen menyelidiki serangan 9 November 2001 dengan memaparkan 3 teori (1) teori konspirasi, serangan dilakukan organisasi teroris yang kompleks dan amat kuat, bahkan menembus intelijen dan pertahanan AS yang dilindungi pejabat AS, (2) segelintir orang pada pemerintahan AS merancang serangan untuk membalikkan perekonomian AS yang menurun. Mereka ingin mencengkeramkan kukunya di Timur Tengah dan rezim Zionis, (3) AS mengalokasikan dana 80 miliar dollar AS untuk mempercanggih senjata nuklir (Suara Merdeka, 25 September 2010).

Dengan demikian, obsesi terwujudnya generasi yang cinta dan fasih membaca al-Quran dan pendakwah yang karakter hidupnya sebagaimana yang diajarkan dalam al-Quran sejak usia dini terwujud didukung oleh lingkungan pendidikan yang disiplin dan tauladan guru yang ideal. Upaya tersebut rentan dicurigai pihak tertentu atas perkembangan Islam dengan julukan gerakan 'lain'.

\section{PENUTUP}

\section{Simpulan}

Pendiri Pondok pesantren Hidayatullah adalah Abdullah Said yang lahir di Kampung Lamatti Rilau, Kecamatan Sinjai Utara, Kabupaten Sinjai, Sulawesi Selatan beretnis Bugis. Pendidikan khasnya di antaranya penanaman cinta al-Quran menjadi kekhasan di SDIT Luqmanul Hakim di Kudus yang visi dan misi lembaganya ada pembeda dengan lembaga pendidikan formal berbendera Islam lainnya. Anak didik identik dengan membawa dan membaca al-Quran meski masih belia. Salat wajib dan sunah berjamaah menjadi rutinitasnya sehingga mentradisi pada usia dewasa. Unsur karakter dalam pendidikan karakter meliputi religiositas, kejujuran, disiplin, cinta damai, tanggung jawab, kreatif, suka membaca alQuran dan menghapalnya dijadikan kebiasaan dan menjadi budaya sekolah. Peran orangtua 
mendukungnya menjadi pembiasaan di rumah. Hal yang diintegrasikan adalah tradisi membaca al-Quran setiap saat, penanaman sikap demokratis dalam pembelajaran, dan berperilaku yang mencerminkan konsep pendidikan karakter.

Karakter gemar membaca dan menghapal al-Quran karena usia anak-anak memerlukan pembiasaan, adanya fasilitas pendukung utama, dan guru sebagai pionir bagi peserta didik sebagai faktor keberhasilan mewujudkan pendidikan karakter. Hal ini merujuk pada Piagam Hidayatullah yang menjadi keharusan menaati bagi warga Hidayatullah.

\section{Rekomendasi}

Keberlangsungan lembaga pendidikan Hidayatullah di Kudus perlu membuat terobosan agar kualitas alumninya semakin unggul. Pertama, fasilitas pembelajaran meliputi media, sumber, dan sarana selalu dioptimalkan dengan pendekatan multimedia yang canggih. Kedua, perekrutan guru mengutamakan profesionalisme agar tidak terkesan eksklusif. Ketiga, membuka peluang kerja sama dengan ragam lembaga agar kesan (dikesankan) eksklusif makin memudar. Keempat, mengader generasi yang menghormati beda agama diwujudkan dengan interaksi lintas agama agar tidak eksklusif. 


\section{DAFTAR PUSTAKA}

A.Doni Koesoema.(2007). Pendidikan Karakter Strategi Mendidik Anak di Zaman Global. Grasindo: Jakarta.

Strategi Pendidikan Karakter. Artikel Harian Kompas, 29 Agustus 2016.

Bagir, Haidar. Problem Pendidikan Karakter. Artikel Harian Kompas, 9 Januari 2013.

Dianto, Ageng Mei (2014). Peranan Lembaga Amil Zakat Nasional Baitul Maal Hidayatullah dalam Meningkatkan Kesejahteraan Mustahiq Kabupaten Tulungagung. Jurnal an-Nisbah, Vol.01, No.01, Oktober.

Jainuri, Achmad. Orientasi Ideologi Gerakan Islam. Lpam: Surabaya, 2004.

Qodir, Zuly. Radikalisme Agama di Indonesia. Pustaka Pelajar: Yogyakarta, 2014.

Rukah. (2019). Peran Amil Zakat Baitul Maal Hidayatullah dalam Pendayagunaan Zakat Melalui Program Senyum Anak Indonesia Studi Kasus di Ponpes al-Burhan Hidayatullah Gedawang, Banyumanik, Kota Semarang. Skripsi Jurusan Manajemen Dakwah Fakultas Dakwah dan Komunikasi UIN Walisongo Semarang.

Rosyid, Moh. (2019). Lembaga Pendidikan dan Kaderisasi Da’i: Studi Kasus pada Lembaga Pendidikan Hidayatullah di Kudus. Jurnal Tasamuh UIN Mataram, Vol.17. No.1.

Sauri, Sofyan dan Achmad Hufad.(2007). Pendidikan Nilai dalam Ilmu dan Aplikasi Pendidikan. Bagian 3. UPI: Bandung.

Salbu, Manshur. (2009). Mencetak Kader: Perjalanan Hidup Ustad Abdullah Said Pendiri Hidayatullah. Surabaya: Suara Hidayatullah Publishing.

Tim Peneliti IAIN Antasari. (2003). Ponpes Hidayatullah Balikpapan. Puslit IAIN Antasari, Banjarmasin.

Zuchdi, Darmiyati. (2008). Humanisasi Pendidikan. Bumi Aksara: Jakarta. 2008.

Zein, Nashrur Rahman.(2018). Ponpes Hidayatullah Yogyakarta di Balong, Donoharjo, Ngaglik, Sleman (19892016 M). Skripsi Jurusan Sejarah dan Kebudayaan Islam Fakultas Adab dan Ilmu Budaya UIN Sunan Kalijaga Yogyakarta. 